\title{
Writers' self-representation in academic writing: The case of computer engineering research articles by English versus Iranian writers
}

Kuhi, Davud

Islamic Azad University, Maragheh Branch, Iran (davud.kuhi@gmail.com)

Tofigh, Marzieh

Islamic Azad University, Maragheh Branch, Iran (M_tofigh82@yahoo.com)

Babaie, Raziyeh

Islamic Azad University, Maragheh Branch, Iran (Hw.tab.au@gmail.com)

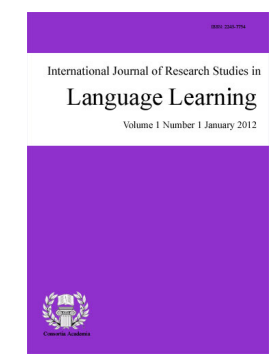

ISSN: 2243-7754 Online ISSN: 2243-7762

OPEN ACCESS

\section{Abstract}

It is widely acknowledged that academic writing is not just about communicating an ideational content; it is also about the representation of self. The purpose of this study was to investigate the tendency of Iranian and American writers for self-representation which is realized by means of writers' explicit (first person self-references) and implicit self (imperative forms and attitude markers) in computer engineering research articles. In this study, 40 published research articles written in English by Iranian and American academics were analyzed to determine the distribution of first person pronouns, imperative forms and attitude markers. We have also examined the semantic references of plural pronoun 'we' as inclusive or exclusive according to their functions. The results indicated that both groups presented themselves both explicitly and implicitly. In addition, in the light of the results, it is evident that Iranian writers utilized explicit 'self' more than American writers did, whereas American writers made use of implicit 'self' more than Iranian scholars.

Keywords: attitude marker; imperative forms; self-representation; exclusive we; inclusive we 


\section{Writers' self-representation in academic writing: The case of computer engineering research articles by English versus Iranian writers}

\section{Introduction}

In recent years, scholars have come to appreciate that writers' self-representation is a central feature of interaction because it plays a prominent role in negotiating the relationship between writers' arguments and their discourse communities, paving the way for writers to create an authorial identity (Hyland, 2001). In fact, all writing conveys information about the writer, but perhaps personal projection is the most powerful means of self-representation (Ivanic, 1998). Thus, writers cannot avoid projecting an impression of themselves and how they stand in relation to their arguments, their community and their readers. The ways that writers represent themselves by their rhetorical choices have been extensively discussed by Ivanic (Ivanic, 1998; Ivanic \& Weldon, 1999).

Broadly speaking, the presence or absence of explicit author references can be considered to be a conscious choice by writers in the sense that the strategic use of self representation is a reflection of writers' conscious projection into text and promotion of authorial self (Ivanic, 1998; Hyland, 2001, 2002a, 2002b, 2005a). It is widely acknowledged that writers' rhetorical decisions regarding a subjective or an impersonal style have prominent impact on how message can be demarcated on the part of audience. In general, writers "gain credibility by projecting an identity invested with individual authority, displaying confidence in their evaluations and commitments to their ideas" (Hyland, 2002a, p. 1091).

In fact, through rhetorical choices of self, authors tend to exhibit a personal voice as knowledgeable contributors of the field. Of course, writers on some occasions also favor impersonal style using passive voice. The preference for being impersonal could be traced in a philosophical movement which is deeply rooted in theoretical underpinning of the positivist assumption (Hyland, 2001, 2002a, 2002b) in the sense that academic writing is merely empirical and objective. In other words, in traditional view, as Hyland (2001) eloquently comments, 'eradication of the self is seen as demonstrating a grasp of scholarly persuasion as it allows the research to speak directly to the reader in an unmediated way' (p.208). In this orientation, it is possible to assume that successful writers make tacit stance choices and assess their interpersonal intrusion into text assuring an impression of personal standing, authority, and credibility (Hyland, 2001, 2002a, 2008).

We believe that, in general, writers' self-representation can be reflected in two ways: explicitly and implicitly. That is to say, writers' self might be realized by means of writers' explicit self (e.g. first person self-references) and implicit self (e.g. imperative forms and attitude markers). As regards explicit self, one of the most obvious ways that writers can affirm their role in the discourse is through first person pronouns (Hyland, 2001; Kuo, 1999; Tang \& John, 1999). The special point that should be mentioned here is that first-person plural pronoun (we) can have either inclusive or exclusive semantic references. An inclusive first-person plural pronoun (inclusive' $w e$ ') includes both speaker-writer and hearer-reader, while an exclusive one (exclusive 'we') excludes hearer-reader. Our point of concern in this study is writers' explicit self vs. implicit self and exclusive we vs. inclusive we.

Indeed, exclusive 'we', as Wales (1980) points out, is the 'collective we' which implies several writers. The use of exclusive "we", despite representing a plural meaning, down plays the reader from the writers' texts thereby reducing interpersonal involvement. In fact, exclusive we collaborates writers to signal their presence as researchers in the paper and characterize specific discourse contexts to emphasize their role in research; in other words, exclusive we is used when writers want to stress their personal standings and contribution to fellow members of their discourse community. 
Writers' self-representation in academic writing: The case of computer engineering research articles

However, inclusive we collaborates the writer to construct a 'chummy' and 'intimate' tone (Wales, 1980), forming a tie between writer and reader (Muhlhausler \& Harre, 1990). More generally, inclusive we performs, among other things, three main functions: a) creating audience involvement by indicating that the argument of the text is being built up by a collaborative writer/reader effort (Wales, 1980), b) ensuring the readers to feel that they are part of a 'joint enterprise' (Quirk, Greenbaum, Leech, \& Svartvik, 1985, p. 350), c) constructing dialogism between writers and the audience by making the discourse reciprocal, in Nystrand's (1989) term, or interactional in Thompson and Thetela's (1995) term.

From this perspective, the linguistic choices writers make, i.e. whether to use exclusive we or inclusive we, not only affect the conceptual or ideational meaning that they convey, but also can influence the impression they make on their readers. Indeed, the intrusion of authorial authority to limit claims, enhance plausibility and promote personal credibility can play an important role in securing acceptance for academic arguments (Hyland, 2005a)

In the light of such insights in recent years, there has been a growing interest in the interactive and rhetorical character of academic writing, expanding the focus of study beyond the ideational dimension of texts to the ways they function at the interpersonal level. A rich array of studies has probed into writers' self-representation in academic arena (e.g. Ivanic, 1998; Tang \& John, 1999; Kuo, 1999; Hyland, 2001; Harwood, 2005a, 2005b). Although researchers have come to recognize that writers' projection of self is pivotal for both native and non-native writers (Hyland, 2002a; Harwood, 2005c; Ivanic \& Camps, 2001), very few cross-cultural studies have been carried out to examine authorial self-representation and even no such studies on the use of writers' self-representation by Iranian and American academics have been conducted in computer engineering. Therefore, the purpose of this study was to investigate the tendency of Iranian and American writers' self-representation which are realized by means of writers' explicit (first person plural self-references) and implicit self (imperative forms and attitude markers) in computer engineering research articles.

To our knowledge, such a study is a rewarding area of research for several reasons: First, since publishing in English is crucial for scholars, they should be equipped with new norms and conventions of writing in order to gain credibility in their discourse community (Paltridge, 1993). Second, it is assumed that knowledge about the strategic use of authorial self is of great value to journal article writers. They must know, in the process of writing an article for publication, how to accentuate their personal contributions to their field of research and how to create solidarity with expected readers and their disciplines. Third, our research tried to show that academic writing is not entirely devoid of writer's self-representation. Finally, since some scholars believe that in hard sciences it is not common to use pronouns to indicate writers' self and researchers try to diminish their individual contribution to the field, we were curious to see how this view applies in computer engineering.

\section{Methods}

\subsection{Corpus}

The corpus of this study consisted of a total of 40 research articles ( approximately 345,385 words) in the field of computer engineering written in English by Iranian and American scholars (see appendix A for full bibliographical information of corpora). As Becher (1989) divides disciplines into two main groups: hard and soft sciences, the discipline of computer engineering can be subsumed under hard sciences. There is a traditional misconception about hard fields arguing that one cannot find traces of writers' self-representation in hard disciplines. For this reason, this study has tried to challenge such an assumption thereby focusing on the field of computer engineering. In general, the issue of 'nativeness' of writers is not always something that could be easily discovered. Therefore, the writers' affiliation and background were used as a guide. The research articles (20 per group) were randomly culled from leading journals provided by means of informant nomination: EURASIP Journal on Wireless Communications \& Networking, International Journal of Distributed Sensor 
Kuhi, D., Tofigh, M., \& Babaie, R.

Networks (IJDSN), EURASIP Journal, IEEE Transactions on Wireless Communications, IET Communications, and Sensors.

Several remarks should be mentioned in designing such a corpus: first, scholars have come to recognize that genres have dynamic nature and change over time (Berkenkotter \& Huckin, 1995; Conner, 1999; Bhatia, 2004; Hyland, 2011). Appreciating this predominant view, the researchers culled from research articles published from 2008 to 2011. Second, taking into account the fact that there is a distinction between rhetorical features of empirical papers and those of theoretical ones (Pho, 2008), only research articles which faithfully pertained to empirical research articles were included in our corpora. Third, all research articles included in the study were multiple-authored. Fourth, all the corpora were scanned and subsequently converted into MSWord format to facilitate accurate word counts. Fifth, all abstracts, acknowledgments, footnotes, end notes, reference lists, and titles were deleted from both word count and analysis.

\subsection{Procedures}

In order to meet the objectives of this study, the whole text were carefully read word by word to identify writer's explicit and implicit forms of self-representation in the corpora. We calculated the frequency of explicit representation of the writer's self as first person plural pronouns which consists of subjective pronoun "we", objective pronoun "us", possessive adjective "our" and implicit ones as imperative forms and attitude markers per 1000 words. Then, we focused on the semantic features of the subjective plural pronoun we as exclusive and inclusive we.

Due to its theoretical and practical advantages (Kuhi \& Behnam, 2010), we examined writers' 'self' based on Hyland's (2005a) model, including elements of self-mentions, attitude markers and imperative forms (engagement markers):

Self-mention: self- mention refers to the degree of explicit author presence in the text measured by the frequency of first- person pronouns and possessive adjectives (I, am, mine, exclusive we, our, ours). Writers cannot avoid projecting an impression of themselves and how they stand in relation to their arguments, their community, and their readers (Hyland, 2001). Take, for instance:

(Ex1). [...] we focus on WiFi infrastructure networks with very different traffic patterns and a distinct bottleneck at the access point. (Ir.RAs 1)

Attitude markers: attitude markers indicate the writer's affective, rather than epistemic attitude to propositions. Instead of commenting on the status of information, it's probable relevance, reliability or truth, attitude markers convey surprise, agreement, importance, obligation, frustration, and so on (Hyland, 2005a). One striking example from our corpora is:

(Ex2).Unfortunately, in practical networks, rate diversity was observed to cause a detrimental effect, (Am. RAs 8)

Engagement markers: Engagement markers are devices that explicitly address readers; either to focus their attention or include them as of authority (Hyland, 2005a). They are signaled mainly by imperatives. In sciences, imperatives often instruct readers how to carry out research process or to perform action in real world:

(Ex3). Note that consistency here involves relations between information at the same level among neighboring points. (Ir. RAs 3)

Due to the fact that self-representation features are highly context-sensitive and multidimensional, the analysis initially was carried out by one of the researchers and the findings were double-checked by the second researcher. In points of conflict, all coders had a discussion in order to reach a unanimous agreement. 


\section{Results and discussion}

\subsection{Overall Frequency of Writers' Self in Comparison}

On the whole, we had the frequency of writers' self as 25.65 per 1000 words out of which 12.37 belonged to Iranians and 12.92 to Americans. This indicates that both Iranian and American scholars represent themselves as authorial selves in computer engineering research articles (RAs) explicitly and implicitly. It seems that today impersonality as a traditional style does not exist in academic writing and scholars try to show identity representation in writing computer engineering RAs in English. In addition, they might be aware of the promotional role of self-representation features (Taavitsainen, 1999). As Berkenkotter and Huckin (1995) assert today's Anglo-Saxon scientists need to promote their work in order to compete in the modern world of publication due to promotional and consumer post-industrial culture. In a similar vein, Duszak (1997) argues that, "An academic (English) text becomes more of a marketable product that must make its way in order to get on the market" (p. 32). Interestingly enough, Iranians have approached this competitive atmosphere by employing heavy use of self-representation features in computer engineering RAs. Quite frequently authors do this in personal terms with a self-promotional purpose, as found by Harwood (2005a) as well. Take for instance, the following examples, taken from our corpora, in which writers state the goal or purpose of the study:

(Ex4). Then, we focus on the link state at equilibrium. The effect of link location and self-interference [...]. (Ir.RAs 10)

(Ex5). [...] we focus on WiFi infrastructure networks with very different traffic patterns and a distinct bottleneck at the access point. (Ir.RAs 1)

Moreover, one may conclude that Iranian scholars represented their self in their English RAs very similarly to their American counterparts. It is also possible to assume that today as Browne (2003) argues, an academic department is very rarely "a unit of advanced intellectual production", and that "people are becoming less oriented toward their home organization or bureaucracy for their identity, status, and advancement, and more toward their professions, their connections with other professionals" (p. 25). Another interpretation can be that as Richardson (2000) accentuates, since "subjectivity, authority, authorship and reflexivity have become one of the key issues confronting the postmodern writer" (p. 520), Iranian scholars in writing RAs like to be subjective and authorial in computer engineering field as American scholars and refute the traditional view of objectivity and impersonality. Table 1 gives us detailed insights into the frequency-based view of the findings.

Turning to the overall frequency of writers' explicit self and implicit self, we found 17.67 and 7.98 per 1000 words, respectively. These findings show that the overall frequency of writers' implicit self (7.98) in both corpora is approximately half of the Writers' explicit self (17.67) suggesting that scholars have more tendency to present their authorial self more explicitly. These findings are also in line with Kuo's (1999) study in which explicit self (first-person plural pronouns) was found to appear far more frequently. The use of first person provides an opportunity for writers to accentuate and to seek agreement for their own contributions. Hence, it is widely acknowledged that using first person is a powerful means by which writers express an identity by allowing their claim to speak as an authority, and this is at the heart of successful academic writing.

Notably, the highest frequency among writers' explicit 'self' belonged to the subjective pronoun' we' with the frequency of 14.32 per 1000 words and the lowest to the objective pronoun ' $u s$ ' with the frequency of $(0.45)$ per 1000 words. We found possessive adjective 'our' (2.95) to be more common than objective pronoun ' $u s$ ' $(0.45)$ in computer engineering RAs in our corpora.

Turning to variations between native and non-native writers, our findings revealed that authors' explicit self was found to be more frequently used by Iranian scholars (9.82) than by American ones (7.85) (See 
Kuhi, D., Tofigh, M., \& Babaie, R.

Table 1). As is evident, Iranian scholars are more prone to apply subjective plural pronoun we (7.94) than American scholars (6.38) in computer engineering RAs. It is worth noting that the underlying cultural and pragmatic motivations of authors lead to their various linguistic choices. In effect, academic texts differ in the degree of authorial presence and the salience of particular components of an academic's social identity (Vassileva, 2000). In fact, the presence or absence of explicit author self is a conscious choice by writers to adopt a particular stance and a contextually situated authorial identity (Hyland, 2001). According to Langacker (1990), the explicit mention of first person pronouns leads to a less subjective and less interpersonal construction than when they are left implicit. Thus, on the basis of the outcomes, it is also possible to infer that American academics are more subjective and interpersonal than Iranian scholars, because American group are more prone to present their authority implicitly.

As regards writers' implicit 'self', Americans presented their implicit self twice more than their non-native peers (5.07 vs. 2.91). Statistically speaking, on the whole, attitude markers had the frequency of 4.23 followed by imperative forms with frequency of 3.75 per 1000 words. As you see in Table 1, the total frequency of attitude markers recorded in American corpus was to some extent greater than Iranian sample (1.82 vs. 2.41).

The attitude expressed can be of many different types: expressions of surprise, of thinking that something is important, or of concession, agreement, disagreement, and so on. The following attitude markers were taken from our analyzed texts:

(Ex6).Unfortunately, in practical networks, rate diversity was observed to cause a detrimental effect,... (Am. RAs 8)

\section{(Ex7). If this time can be cut down significantly by designing the hardware to have the ability to rapidly change channels... (Am. RAs 7)}

Some authors employed a positive or a negative assessment of their own research, mainly in the discussion section of their RAs. By referring to the limitations of their research, authors may expect the possible readers' critiques and, thus, they can contribute to saving their face (Brown \& Levinson, 1987; Myers, 1989). For example:

(Ex8). [...] we were unable to model some types of overhead, such as the random amount of time a node backs off [...]. (Ir.RAs 3)

Furthermore, scholars can indicate the strengths of their research, highlight their main contribution(s), and portray their authorial self:

(Ex9). Thus, the theoretical model we report displays much greater fit than the alternative efficiency models. (Ir.RAs 5)

As regards imperatives, Iranian writers made use of imperative forms significantly less than their peers (1.09 vs. 2.66). An imperative brings attention to the statement that follows, usually an action (Kuo, 1999), thereby fulfilling the interactive and command-like function. In fact, imperatives direct the reader to some action and so function to position readers by setting up premises or highlighting what they should attend to in the argument (Hyland, 2004). We found these types of imperatives in our examined corpora in the Materials and Methods sections of the articles with verbs of supposition or attention like assume, suppose, note, observe, or consider:

(Ex10). Note that consistency here involves relations between information at the same level among neighboring points. (Ir. RAs 3) 
Writers' self-representation in academic writing: The case of computer engineering research articles

Table 1

Writers' overall categorical' self' in comparison

\section{Writers' Self}

\begin{tabular}{|c|c|c|c|c|c|c|c|c|}
\hline \multicolumn{5}{|c|}{ Explicit Self } & \multicolumn{3}{|c|}{ Implicit self } & \multirow{2}{*}{ Totals } \\
\hline Corpora & we & us & Our & Total & $\begin{array}{c}\text { Imperative } \\
\text { forms }\end{array}$ & $\begin{array}{l}\text { Attitude } \\
\text { markers }\end{array}$ & Total & \\
\hline $\begin{array}{l}\text { Iranian } \\
\text { corpus }\end{array}$ & 7.94 & 0.26 & 1.62 & 9.82 & 1.09 & 1.82 & 2.91 & 12.73 \\
\hline $\begin{array}{l}\text { American } \\
\text { corpus }\end{array}$ & 6.38 & 0.19 & 1.33 & 7.85 & 2.66 & 2.41 & 5.07 & 12.92 \\
\hline Overall & 14.32 & 0.45 & 2.95 & 17.67 & 3.75 & 4.23 & 7.98 & 25.65 \\
\hline
\end{tabular}

To better illustrate these findings, Figure 1 gives us a general view of categories of writers' 'self ' in the corpus.

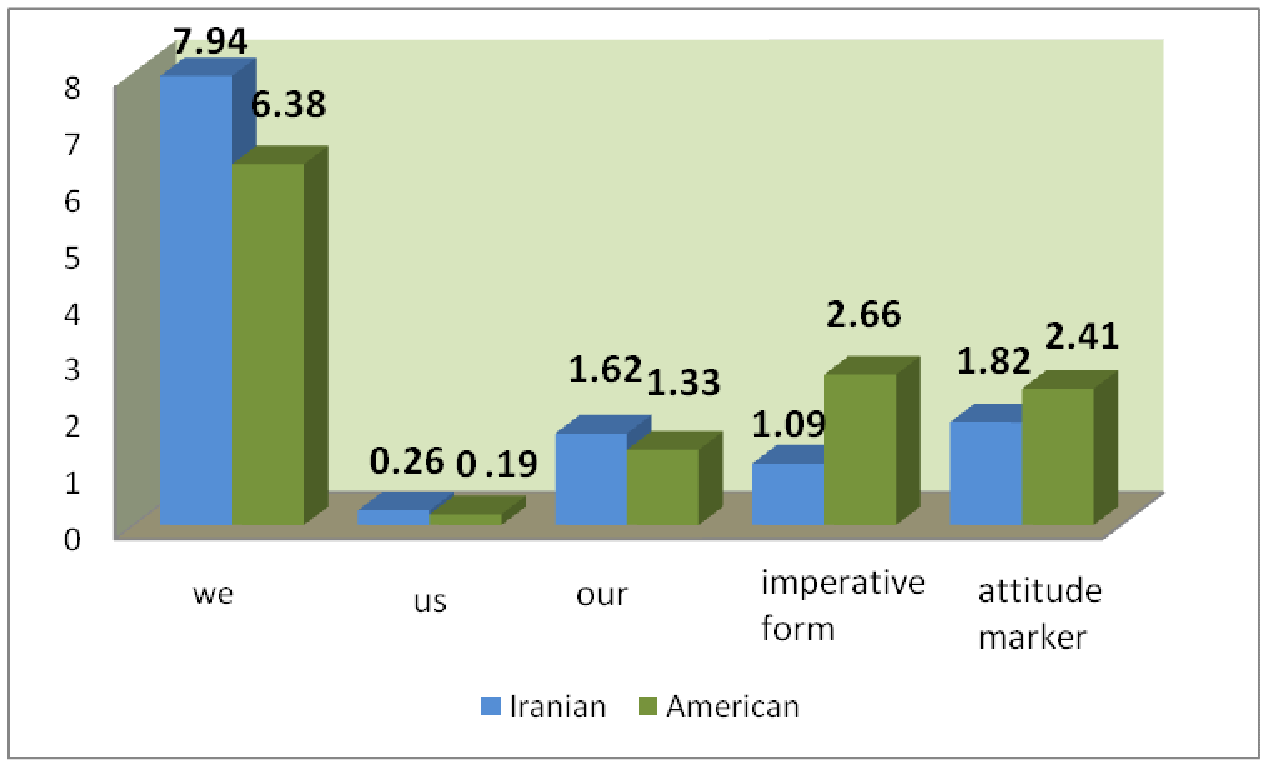

Figure 1. Writers' overall categorical self in comparison

\subsection{Subjective plural pronoun we: Exclusive vs. Inclusive we}

As noted earlier, first-person plural pronoun can have either inclusive or exclusive semantic references. An inclusive first-person plural pronoun includes both speaker-writer and hearer-reader, while an exclusive one excludes hearer-reader. The results indicate that frequency of exclusive we in Iranian corpus was 7.68, while in American corpus it was 6.05 (per 1000 words). Hence, it is possible to deduce that Iranian scholars are more prone to apply exclusive we than American scholars in computer engineering RAs. However, the frequency of inclusive 'we' in Iranian group was 0.26 and in American one it was 0.33 per1000 words (See Table 2). 
Kuhi, D., Tofigh, M., \& Babaie, R.

Table 2

Frequency of Exclusive we vs. Inclusive we

\begin{tabular}{llll}
\hline & Exclusive we & Inclusive we & Total \\
Iranian & 7.68 & 0.26 & 7.94 \\
American & 6.05 & 0.33 & 6.38 \\
\hline
\end{tabular}

Examples from our examined texts show how the writers strategically use exclusive we to refer to themselves or inclusive we to refer to either writers and readers or the discipline as a whole for different communicative purposes (Kuo, 1999). Exclusive we in our corpora were found to fulfill different rhetorical functions (Harwood, 2005a), as illustrated in the following examples:

(1). Stating a goal or purpose

(Ex11). In this paper, we are concerned with the carrier collection necessary to support stimulated emission in ultrathin quantum wells. (Am. RAs 8)

(2). Explaining what writers did in research

(Ex12). We consider an OFDMA 802.16 cellular network. The uplink and the downlink are assumed... (Ir. RAs 18)

(3). Proposing a theory or approach

(Ex13).In the coming paper, we proposed a new QoS improving method based on prioritization. (Ir. RAs 18)

(4). Showing results or findings

(Ex14). We found that large numbers of packets being dropped, especially during the relay process, has an adverse effect on the gain because of the large overhead...(Am. RAs 8)

(5). Showing commitment or contribution to research

(Ex15). Finally, we believe that LEW satisfies better the important criterion of comprehensibility... (Ir. RAs 19)

(6). Comparing approaches, viewpoints

(Ex16). ...this topic has been addressed for image processing applications by Wilson and Granlund [14]. We next address this issue from an analytical viewpoint, ... (Ir. RAs 20)

(7). Expressing wish or expectation

(Ex17). Also, we would expect that the higher the network dynamics, that is, the higher the mobility, number, and ... (Am. RAs 9)

(8) Making a claim or statement, elaborating an argument

(Ex18). First, we suggest using a multi-hop sensor network connected by radio frequency [...]. (Am. RAs 3)

(9)Outlining the steps followed in the RA 
Writers' self-representation in academic writing: The case of computer engineering research articles

(Ex19).At this stage, we apply (15) to adaptively compute CWmin as a function of $n(t)$ (which is an estimation of channel traffic). Finally, this initial window value will be [...]. (Ir.RAs 18)

The above-mentioned discourse functions reveal where and how writers use exclusive we to signal their presence as researchers in the paper; they also characterize specific discourse contexts where writers want to emphasize their role in research. In fact, exclusive we is used where writers want to stress a personal contribution to their field of research.

As regards inclusive we, by using inclusive we which involves both writers and readers in the same activity, the writers presuppose readers background knowledge and ability to follow the arguments. The use of inclusive we shortens the distance between writers and readers and stresses solidarity with readers. The examples below, taken from the examined corpus, may illustrate the function:

(Ex20). We will see that this relationship is reversed (e.g., detection becomes more likely than coverage) when a network of smaller sensors is employed. (Am. RAs 10)

This effort to involve the readership can, thus, be regarded as a manifestation of positive politeness. As Hyland (2001) comments, " By referring to the reader, and by crediting them with (imaginary) intelligent questions or observations, the writer apparently transmits communality and positive politeness by acknowledging the audience as disciplinary equals: in one of Hyland's researcher informant's words, the writer is 'getting [their] readers inside" ( p. 559).

In addition, the inclusive ' $w e$ ' can be employed in order to diminish writer responsibility (Muhlhausler \& Harre, 1990; Harwood, 2005b) in the sense that researchers need to be cautious while using inclusive 'we' as it conveys an impression of collectivism and responsibility of their knowledge claims. Of course, either inclusive or exclusive we can be used for a discourse function of hedging a proposition or claim (Salagar-Meyer, 1994; Myers, 1989) in order to show modesty by tentative statements and giving room for alternative views. In the analyzed texts, we co-occurred with verbs like assume to perform the discourse function of hedging a proposition or claim:

(Ex21). Without loss of generality we assume that these columns are the first $k$ columns of $G ;. . .($ Ir. RAs19)

\section{Conclusion}

We have carried out a contrastive study of research articles written in English in two cultural groups of Iranian and American writers in the field of computer engineering. Notably, one might think that the frequency of the writers' self-representation between two groups is roughly the same. No significant difference was found between the overall frequency of the Iranian and American corpus. In other words, both Iranian and American scholars represent themselves as authorial selves in RAs explicitly and implicitly. In the light of the results, it is clear that Iranian writers used explicit self slightly more than American writers did; on the other hand, American writers used implicit self two times more than Iranian authors. From a pedagogical standpoint, exploring writers' self is really noteworthy.

In fact, the findings of this study will broaden ESP and EAP teachers' views to the recent tendency of researchers in employing self-representation categories in computer engineering RAs. Moreover, ESP/EAP teachers should apply this view in their teaching course to draw the attention of students to this aspect of self-representation. Also, syllabus designers and material developers can provide tasks which raise the awareness of novice writers about self-representation in academic writing. It is worth noting that this study is only limited to research articles in the computer engineering and also it is only limited to the use of first person plural pronouns (writers' explicit self) and attitude markers and imperative forms (writers' implicit self). Definitely, there is a need for further research in various genres and disciplines and different aspects of self-representation. 


\section{References}

Becher, T. (1989). Academic tribes and territories: Intellectual enquiry and the cultures of disciplines. Milton

Berkenkotter, C., \& Huckin, T. (1995). Genre knowledge in disciplinary communication. Hillsdale, NJ: Lawrence Erlbaum.

Bhatia, V. K. (2004). Worlds of written discourse: A genre-based view. London and New York: Continuum.

Brown, P., \& Levinson, S. (1987). Politeness: Some universals in language usage. Cambridge: CUP.

Browne, S. (2003). Digital epidermalization: Race, identity and biometrics. Critical Sociology, 36(1), 131-150. http://dx.doi.org/10.1177/0896920509347144

Conner, U. (1999). Contrastive rhetoric: Cross-cultural aspects of second language writing. Cambridge University Press.

Duszak, A. (1997). Cross-cultural academic communication: A discourse community views. In A. Duszak (Ed.), Culture and styles of academic discourse (pp. 11-39). Berlin: Mouton de Gruyter. http://dx.doi.org/10.1515/9783110821048.11

Harwood, N. (2005a). Nowhere has anyone attempted...In this article I aim to do just that. A corpus-based study of self-promotional I_and WE_in academic writing across four disciplines. Journal of Pragmatics, 37(8), 1207-1231. http://dx.doi.org/10.1016/j.pragma.2005.01.012

Harwood, N. (2005b). We do not seem to have a theory. The theory I present here attempts to fill this gap: Inclusive and exclusive pronouns in academic writing. Applied Linguistics, 26(3), 343-375. http://dx.doi.org/10.1093/applin/ami012

Harwood, N. (2005c). I hoped to counteract the memory problem, but I made no impact whatsoever: Discussing methods in computing science using I. English for Specific Purposes, 24(3), 243-267. http://dx.doi.org/10.1016/j.esp.2004.10.002

Hyland, K. (2001). Humble servants of the discipline? Self-mention in research articles. English for Specific Purposes, 20, 207-226. http://dx.doi.org/10.1016/S0889-4906(00)00012-0

Hyland, K. (2002a). Authority and invisibility: authorial identity in academic writing. Journal of Pragmatics, 34(8), 1091-1112. http://dx.doi.org/10.1016/S0378-2166(02)00035-8

Hyland, K. (2002b). Options of identity in academic writing. ELT Journal, 56(4), 351-358. http://dx.doi.org/10.1093/elt/56.4.351

Hyland, K. (2004). Disciplinary interactions: Meta-discourse in L2 postgraduate writing, Journal of Second Language Writing, 13, 133-151. http://dx.doi.org/10.1016/j.jslw.2004.02.001

Hyland, K. (2005a). Meta-discourse: Exploring interaction in writing. London: New York.

Hyland, K. (2008). Persuasion, interaction, and the construction of Knowledge. International Journal English Studies, 8, 1-23.

Hyland, K. (2011). Academic discourse. In K. Hyland \& B. Paltridge (Eds.), Companion to discourse analysis (pp. 171-184). London: Continuum Press.

Ivanic, R. (1998).Writing and identity: The discoursal construction of identity in academic writing. Amsterdam: John Benjamins.

Ivanic, R., \& Camps, D. (2001). I am how I sound: Voice as self-representation in L2 writing. Journal of Second Language Writing, 10, 3-33.

Keynes: The Society for Research into Higher Education and Open University Press.

Kuhi, D., \& Behnnam, B. (2011). Generic variations and metaediscourse use in the writing of applied linguists: A comparative study and preliminary framework. Written Communication, 28(1), 1-45. http://dx.doi.org/10.1177/0741088310387259

Kuo, C. H. (1999). The use of personal pronouns: Role relationships in scientific journal articles. English for Specific Purposes, 18(2), 121- 138. http://dx.doi.org/10.1016/S0889-4906(97)00058-6

Langacker, R. W. (1990). Subjectification. Cognitive Linguistics, 1, 5-38. http://dx.doi.org/10.1515/cogl.1990.1.1.5

Muhlhausler, P., \& Harre, R. (1990). Pronouns and people: The linguistic construction of social and personal identity. Oxford: Basil Blackwell. 
Writers' self-representation in academic writing: The case of computer engineering research articles

Murduenas, P. (2007). I/we focus on...: A cross-cultural analysis of self-mentions in business management research articles. Journal of English for Academic Purposes, 6, 143-162. http://dx.doi.org/10.1016/j.jeap.2007.05.002

Myers, G. (1989). The pragmatics of politeness in scientific articles. Applied Linguistics, 10, 1-35. http://dx.doi.org/10.1093/applin/10.1.1

Nystrand, M. (1989). A social-interactive model of writing. Written Communication, 6(1), 66-85. http://dx.doi.org/10.1177/0741088389006001005

Paltridge, B. (1993). Writing up research: A systemic functional perspective. System, 21(2), 175-192. http://dx.doi.org/10.1016/0346-251X(93)90040-N

Pho, P. D, (2008). Research article abstracts in applied linguistics and educational technology: A study of linguistic alizations of rhetorical structure and authorial stance. Discourse Studies, 10(2), 231250. http://dx.doi.org/10.1177/1461445607087010

Quirk, R., Greenbaum, S., Leech, G., \& Svartvik, J. (1985). A comprehensive grammar of the English language. Oxford: Longman.

Richardson, L. (2000). Evaluating ethnography. Qualitative Inquiry, 6(2), 253-255. http://dx.doi.org/10.1177/107780040000600207

Salager-Meyer, F. (1994). Hedges and textual communicative function in medical English written discourse. English for Specific Purposes, 13(2), 149-170. http://dx.doi.org/10.1016/0889-4906(94)90013-2

Taavitsainen, I. (1999). Metadiscursive practices and the evolution of early English medical writing (13751550). In J. M. Kirk (Ed.), Corpora galore: Analyses and techniques to describe English (pp. 191-207). Amsterdam: Rodopi.

Tang, R., \& John, S. (1999). The "I" in identity: Exploring writer identity in student academic writing through the first person pronoun. English for Specific Purposes, 18, 23-39. http://dx.doi.org/10.1016/S0889-4906(99)00009-5

Thompson, G., \& Thetela, P. (1995).The sound of one hand clapping: The management of interaction in written discourse. TEXT, 15(1), 103-27. http://dx.doi.org/10.1515/text.1.1995.15.1.103

Vassileva, I. (2000).Who is the author? A contrastive analysis of authorial presence in English, German, French, Russian and Bulgarian academic discourse. International Journal of Applied Linguistics, 2, 10-25.

Wales, K. (1980). Exophora re-examined: The uses of we in present-day English. UEA Papers in Linguistics, 12, 21-44. 


\section{Appendix A}

\section{Research articles in the corpus}

\section{Iranian sub-corpus}

(1) Aghdasi, H. Abbaspour, M., \& Bisadi, H. (2009). High-resolution images with minimum energy dissipation and maximum field-of-view in camera-based wireless multimedia sensor networks. Sensors 2009, 9, 6385-6410.

(2) Aghdasi, H., \& Abbaspour, M. (2008). An energy-efficient and high-quality video transmission architecture in wireless video-based sensor networks. Sensors 2008, 8, 4529-4559.

(3) Ashtiani, F., Salehi, J., \& Aref, M. (2003). Mobility modeling and analytical solution for spatial traffic distribution in wireless multimedia networks. IEEE Journal, 21(10), 1699-1709.

(4) Babaie, S., KhademZade, H., \& Hosseinalipour, A. (2010). New clustering method to decrease probability of failure nodes and increasing the lifetime in WSNs. International Journal of Computer Science and Information Security, 7(2), 73-76.

(5) Babaei, S. H., Aghaalizadeh, S., \& Golsorkhtabar, M. (2010). The new clustering algorithm with cluster members bounds for energy dissipation avoidance in wireless sensor network. International Conference on Computer Design and Applications, 2, 191-195.

(6) Babaei, S. H., Aghaalizadeh, S., \& Golsorkhtabar, M. (2010). The novel threshold based hierarchical clustering method for wireless sensor networks. International Conference on Electronics and Information Engineering, 3, 201-210.

(7) Babaei, S. H., \& Nobahari, S. (2010). A new stream cipher based security architecture for wireless sensor networks. International Conference on Intelligent Network and Computing, 1, 288-292.

(8) Delgosha, F., \& Fekri, F. (2009). A multivariate key-establishment scheme for wireless sensor networks, IEEE Transactions on Wireless Communication, 8(4), 100-106.

(9) Fathi, M., Taheri, H., \& Mehrjo, M. (2010). Cross-layer joint rate control and scheduling for OFDMA wireless mesh networks. Transactions on Wireless Communication, 59(8), 1814-1824.

(10) Ghasemi, A., \& Faez, K. (2008). Power-aware MAC for multi-hop wireless networks: A cross layer approach. IEEE Transactions on Wireless Communication, 7(10), 3917-3929.

(11) Goudarzi, P., Tadayon, M., \& Mousavinejad, M. (2009). An optimization theoretic framework for video transmission with minimal total distortion over wireless networks. EURASIP Journal on Wireless Communications and Networking, 598063, 1-15.

(12) Hajjarian Kashani, Z., \& Shiva, M. (2007). Power optimized channel coding in wireless sensor networks using low-density parity-check codes. IET Communication, 2007, 1(6), 1256-1262.

(13) Khadivi, A., \& Shiva, M. (2007). FTPASC: A fault tolerant power aware protocol with static clustering for wireless sensor networks. IEEE Journal, 1(6), 397-401.

(14) Pashazadeh, S., \& Sharifi, M. (2009). Determining the best sensing coverage for 2-dimensional acoustic target tracking. Sensors, 9, 3405-3436.

(15) Pashazadeh, S., \& Sharifi, M. (2009). A geometric modelling approach to determining the best sensing coverage for 3-dimensional acoustic target tracking in wireless sensor networks. Sensors, 9, 6764-6794. 
Writers' self-representation in academic writing: The case of computer engineering research articles

(16) Rezgah, R. E., \& Mohammadi, A. (2007). Capacity estimation of wireless ad hoc networks in fading channels. IET Communication, 2009, 3(2), 293-302.

(17) Sharifi, M., Aminfar, A., \& Abdollahzadeh, E. (2009). A minimalist path detection approach for wireless sensor networks. International Journal of Distributed Sensor Networks, 5, 576-595.

(18) Tadayon, N., \& Zokaei, S. (2010). Introducing an adaptive method to tune initial backoff window (CWmin-ATM) in IEEE 802.11 wireless networks. EURASIP Journal on Wireless Communications and Networking, 323598, 1-14.

(19)Zamani, M., \& Lahouti, F. (2007). Distributed source coding using symbol-based and non-binary turbo codes: Applications to wireless sensor networks. IET Communication, 2(8), 1089-1097.

(20)Zoghi, M., \& Kahaei, M. H. (2010). Adaptive sensor selection in wireless sensor networks for target tracking. IET Signal Process, 4(5), 530-536.

\section{American sub-corpus}

(1) Liang, B. Y., Frolik, J., \& Wang, X. (2009). Energy-efficient dynamic spatial resolution control for wireless sensor clusters. International Journal of Distributed Sensor Networks, 5, 361-389.

(2) Calcev, J., \& Bonta, J. (2009). OFDMA cellular networks with opportunistic two-hop relays. EURASIP Journal on Wireless Communications and Networking, 702659, 1-9.

(3) Casey, K., Lim, A., \& Dozir, G. (2008). Sensor network architecture for tsunami detection and response. International Journal of Distributed Sensor Networks, 4, 27-42.

(4) Challa, N., \& Cam, H. (2010). Class-based fair code allocation with delay guarantees for OVSF-CDMA and VSF-OFCDM in next-generation cellular networks. EURASIP Journal on Wireless Communications and Networking , 738325, 1-22.

(5) Commuri, S., Tadigotla, V., \& Atiquzzaman, M. (2008). Reconfigurable hardware based dynamic data aggregation in wireless sensor networks. International Journal of Distributed Sensor Networks, 4, 194-212.

(6) Dalton, A., \& Hallsrtom, J. (2009). An interactive, source-centric, open test bed for developing and profiling wireless sensor systems. International Journal of Distributed Sensor Networks, 5, 105-138.

(7) David, J., \& Madria, S. (2010). Distributed phased arrays and wireless beam forming networks. International Journal of Distributed Sensor Networks, 5, 283-302.

(8) Jow, A., \& Schurgers, C. (2009). Borrowed channel relaying: A novel method to improve infrastructure network throughput. EURASIP Journal on Wireless Communications and Networking, 174730, 1-12.

(9) Lorca, J., Milner, S., \& Davis, Ch. (2010). Molecular system dynamics for self-organization in heterogeneous wireless networks. EURASIP Journal on Wireless Communications and Networking, 548016, $1-13$.

(10) Nelson, J., Rowe, E., \& Carter, J. (2009). Detection capabilities of randomly-deployed sensor fields. International Journal of Distributed Sensor Networks, 5,708-728.

(11) Ozgur Sanli, H., \& Cam, H. (2010). Collaborative event-driven coverage and rate allocation for event miss-ratio assurances in wireless sensor networks. EURASIP Journal on Wireless Communications and Networking, 345052, 1- 20.

(12) Pagadarai, S., \& Wyglinski, A. (2010). A linear mixed-effects model of wireless spectrum occupancy. EURASIP Journal on Wireless Communications and Networking, 203178, 1-7. 
Kuhi, D., Tofigh, M., \& Babaie, R.

(13) Panja, B., \& Madria, S. (2009). Node security in hierarchical sensor networks: Distribution of functions versus keys. International Journal of Distributed Sensor Networks, 5, 531-556.

(14) Park, J., \& Sahni, S. (2009). Power assignment for symmetric communication in wireless sensor networks. International Journal of Distributed Sensor Networks, 5, 185-200.

(15) Redfield, S., \& Chiang, P. (2011). Experimental characterization of a UWB channel for body area networks. EURASIP Journal on Wireless Communications and Networking, 703239, 1-11.

(16) Roy-Chowdhury, A., \& Baras, J. (2011). Energy-efficient source authentication for secure group communication with low-powered smart devices in hybrid wireless/satellite networks. EURASIP Journal on Wireless Communications and Networking, 392529, 1-18.

(17) Sabbineni, H., \& Chakrabarty, K. (2010). Data collection in event-driven wireless sensor networks with mobile sinks. International Journal of Distributed Sensor Networks, 402680, 1-12.

(18) Sabbineni, H., \& Chakrabarty, K. (2010). An energy-efficient data delivery scheme for delay-sensitive traffic in wireless sensor networks. International Journal of Distributed Sensor Networks, 792068, 1-14.

(19) Shila, D., \& Anjali, T. (2010). An interference-aware admission control design for wireless mesh networks. EURASIP Journal on Wireless Communications and Networking, 106520, 1-16.

(20) Wimalajeewa, T., \& Jayaweera, S. (2011). Distributed and collaborative node mobility management for dynamic coverage improvement in hybrid sensor networks. EURASIP Journal on Wireless Communications and Networking, 724136, 1-17. 